\title{
Resuscitation from drowning
}

\author{
A. D. REDMOND AND T. S. MALLIKARJUN \\ Department of Accident and Emergency Medicine, Stockport Infirmary, Stockport.
}

\section{SUMMARY}

The resuscitation of a 21 -year-old man after submersion in fresh water for at least $5 \mathrm{~min}$ is described. On admission to hospital the patient appeared dead with fixed dilated pupils, deep cyanosis and asystole. Twenty min later the patient was transferred to the intensive care unit with a recordable blood pressure. On arrival there he was breathing spontaneously and so was not ventilated. A few hours later he developed pulmonary oedema and died.

\section{HISTORY}

A 21-year-old man, Mr P. W. was seen to dive into a quarry on one of the hottest days last summer. He did not resurface and friends and passers-by were unable to find him. A policeman was summoned who dived in, and managed to locate the body which was trapped by the feet. Eventually the patient was brought to the shore and expired air ventilation and closed chest cardiac massage instituted. An ambulance then rapidly transferred him to the Accident and Emergency Department at Stockport Infirmary. He had been submerged for at least 5 and possibly $10 \mathrm{~min}$. The journey to the hospital added another $5 \mathrm{~min}$.

On arrival at the hospital he was deeply cyanosed, apnoeic and his pupils were fixed and dilated. A cardiac tracing showed asystole. He was immediately given intra-cardiac injections of $1 \mathrm{mg}$ of Atropine followed by $10 \mathrm{ml}$ of 1:10000 Ardenaline. An endotracheal tube was passed and the patient ventilated with $100 \%$ oxygen. The right subclavian vein was cannulated whilst closed chest cardiac compression was continued. A few minutes later spontaneous ventricular complexes were noted on the ECG which rapidly assumed the pattern of normal sinus rhythm. His rectal temperature was noted to be $35 \cdot 6^{\circ} \mathrm{C}$.

Approximately $15 \mathrm{~min}$ after arrival his pulse rate was 80 and regular and blood pressure recordable at $140 / 70 \mathrm{~mm} \mathrm{Hg}$. The pupils remained fixed and dilated but he

Correspondence: $\operatorname{Dr}$ A. D. Redmond, Department of Accident and Emergency Medicine, Stockport Infirmary, Stockport SK1 3UF 
began responding to painful stimuli. He was given $80 \mathrm{mg}$ of frusemide intravenously. A sample from the femoral artery was sent for blood gas estimation and $50 \mathrm{mls}$ of $8.4 \% \frac{\mathbb{D}}{0}$ sodium bicarbonate given via the central line. A chest X-ray showed a right pneumoth- 3 orax which was drained with an axillary inter-costal drain. The blood gas results were응 reported as shown in Table 1 and the patient given a further $50 \mathrm{mls}$ of $8.4 \%$ sodium $\overrightarrow{\vec{s}}$ bicarbonate. The patient was then transferred by ambulance to a nearby intensive care unit.

Table 1 Blood cases (Corrected for temperature)

\begin{tabular}{lcl}
\hline $\mathrm{pH}$ & $6 \cdot 48$ & \\
$\mathrm{pCO}_{2}$ & $15 \cdot 7$ & $\mathrm{kPa}$ \\
$\mathrm{pO}_{2}$ & $18 \cdot 7$ & $\mathrm{kPa}$ \\
Standard $\mathrm{HCO}_{3}$ & $<4$ & $\mathrm{mmol} / 1$ \\
Base excess & deficit $>30$ & $\mathrm{mmol} / 1$ \\
\hline
\end{tabular}

On arrival at the intensive care unit the patient was found to be breathingspontaneously, maintaining his pulse and blood pressure and the pupils responding to ${ }^{\omega}$

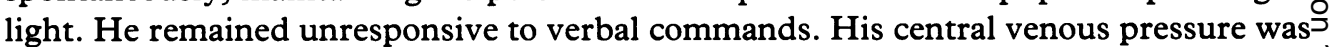
$19 \mathrm{~cm}$ water. A decision not to electively ventilate the patient was made by the medical $\vec{c}$ staff of the intensive care unit. The patient continued to improve for a few hours but then became cyanosed. The hypoxaemia could not be reversed and pulmonary oedema $\vec{\oplus}$ rapidly developed. He was then given intermittent positive pressure ventilation batto asystole ensued from which he could not be resuscitated. A postmortem examination showed no evidence of head injury or gross evidence of brain damage. The lungs we heavily congested but there was no evidence of chest injury. The heart and other organts were normal. The cause of death was stated as drowning.

\section{DISCUSSION}

The reason why this patient got into difficulties in the water is not clear. He certainlyo seemed to have been trapped but whether this was the primary reason is not absolutely. certain. During the warm summer last year it was reported in the popular press that there seemed to be an increased incidence of drownings. These followed a similar pattern of young fit people diving into pools to cool off. It is possible that the change in temperature between the warm skin of the face and the relatively cold water couldo stimulate receptors in the face and oropharynx and trigger a vagally-mediated reflex or apnoea, bradycardia and vasoconstriction - 'the diving response'. Hypoxia alone can lead to carotid-body chemoreceptor excitation and vagally-mediated bradycardia even to the point of asystole (Daly et al., 1979). Although he was not in the water long enough ${ }_{\sigma}^{\omega}$ to cool to any significant degree he had become profoundly hypoxic with a marked acidosis. As far as we are aware, the $\mathrm{pH}$ is the lowest recorded in anyone who was resuscitated (Modell, 1978). The success of the initial resuscitation highlights the fact: that one must not lose hope too soon in victims of near-drowning. Hypothermia may 
often develop and survival after 40 min submersion has been recorded in a child when this occurred (Siebke et al., 1975).

In particular, the pupils alone do not provide evidence of irreversible brain damage. The fact that the patient was in asystole but responded quickly to resuscitative measures would support the hypothesis that vagal reflexes were involved. Expansion of the lungs by inhalation and administration of Atropine would both serve to take off the vagal influence and allow the heart to respond to further resuscitative measures. The fact that the patient had a pneumothorax on the right side is most likely the result of resuscitative measures. The cannulation of a sub-clavian vein whilst chest compression and intermittent positive pressure ventilation are being carried out must increase the likelihood of pneumothorax. This possibility must always be borne in mind during the management of cardiac arrest.

It is well known that patients may survive an episode of near-drowning only to die within hours from so called 'secondary drowning'. Pulmonary oedema in these cases has been caused by destruction and washout of surfactant by aspirated water resulting in alveolar collapse and leakage of plasma into the alveoli (Giammona \& Modell, 1967). The application of intermittent positive pressure ventilation and in particular positive end expiratory pressure can go some way to prevent these changes developing (Modell et al., 1974). If a patient has had any respiratory difficulties then even if breathing spontaneously it has been recommended he is ventilated immediately after resuscitation (Golden, 1980).

When he left the accident and emergency department for transfer to the intensive care unit some five miles away, he required intermittent positive pressure ventilation with a self-expanding bag and endotracheal tube. Towards the end of the journey he started to resist ventilation. He was therefore allowed to breathe spontaneously for the last few min of the journey. The staff of the intensive care unit therefore received a patient who appeared to be much better than was originally described and managing to breathe for himself. They did not wish to interfere and elected to observe him. He was therefore not given positive end expiratory pressure and 'secondary drowning' developed from which he subsequently died. It is now our policy to paralyse all patients who require ventilation prior to transfer.

\section{REFERENCES}

Daly I. De B., Angell-James J. E. \& Elsner R. (1979) Role of carotid-body chemoreceptors and their reflex interaction in bradycardia and cardiac arrest. Lancet $\mathrm{i}, 764-7$.

Giammona S. T. \& Modell J. H. (1967) Drowning by total immersion: effects on pulmonary surfactant of distilled water, isotonic saline and sea water. American fournal of Diseases of Children 114, 612-6.

Golden G. St. C. (1980) Problems of immersion British fournal of Hospital Medicine 23 4, 271-83.

Modell J. H., Calderwood H. W., Ruiz B. C., Downs J. B. \& Chapman R. Jr. (1974) Effects of ventilatory patterns on arterial oxygenation after near-drowning in sea water Anesthesiology 40, 376-84.

Modell J. H. (1978) Biology of Drowning Annual Review of Medicine 29, 1-8.

Siebke H., Breivik H., Rod T. \& Lind, B. (1975) Survival after 40 min submersion without cerebral sequelae Lancet 1, 1275-7.

Received 23 fanuary 1984; accepted for publication 16 February 1984.

This paper was presented at the Scientific Meeting of the Emergency Medicine Research Society, 9-10 September, 1983 in York. 